\title{
An investigation into the beneficial effects of high-dose interferon beta 1-a, compared to low-dose interferon beta 1-a (the base therapeutic regimen) in moderate to severe COVID-19: A structured summary of a study protocol for a randomized controlled I trial
}

Ilad Alavi Darazam ${ }^{1,2^{*}}$, Firouze Hatami ${ }^{1}$, Mohammad Mahdi Rabiei ${ }^{1}$, Mohamad Amin Pourhoseingholi ${ }^{3}$, Omid Moradi ${ }^{4}$, Shervin Shokouhi ${ }^{1}$, Mohammad Reza Hajesmaeili ${ }^{5}$, Minoosh Shabani ${ }^{1}$ and

Seyed Sina Naghibi Irvani ${ }^{1}$

\begin{abstract}
Objectives: We will investigate the effectiveness of high dose Interferon Beta 1a, compared to low dose Interferon Beta 1a (the base therapeutic regimen) in COVID-19 Confirmed Cases (Either RT-PCR or CT Scan Confirmed) with moderate to severe disease

Trial Design: This is a single center, open label, randomized, controlled, 2-arm parallel group (1:1 ratio), clinical trial. Participants: The eligibility criteria in this study is: age $\geq 18$ years, oxygen saturation (SPO2) $\leq 93 \%$ or respiratory rate $\geq 24$, at least one of the following manifestation: radiation contactless body temperature $\geq 37.8$, Cough, shortness of breath, nasal congestion/ discharge, myalgia/arthralgia, diarrhea/vomiting, headache or fatigue on admission. The onset of the symptoms should be acute ( $\leq 14$ days). The exclusion criteria include refusal to participate, using drugs with potential interaction with lopinavir/ritonavir or interferon- $\beta 1$ a, blood ALT/AST levels $>5$ times the upper limit of normal on laboratory results, pregnant or lactating women, history of alcohol or drug addiction in the past 5 years, the patients who be intubated less than one hours after admission to hospital.

This study will be undertaken at the Loghman Hakim Hospital, Shahid Beheshti University of Medical Sciences.

* Correspondence: ilad13@yahoo.com

1 Infectious Diseases and Tropical Medicine Research Center, Shahid Beheshti University of Medical Sciences, Tehran, Iran

${ }^{2}$ Department of Infectious Diseases, Loghman Hakim Hospital, Shahid Beheshti University of Medical Sciences, Tehran, Iran

Full list of author information is available at the end of the article

C The Author(s). 2020 Open Access This article is licensed under a Creative Commons Attribution 4.0 International License, which permits use, sharing, adaptation, distribution and reproduction in any medium or format, as long as you give appropriate credit to the original author(s) and the source, provide a link to the Creative Commons licence, and indicate if changes were made. The images or other third party material in this article are included in the article's Creative Commons licence, unless indicated otherwise in a credit line to the material. If material is not included in the article's Creative Commons licence and your intended use is not permitted by statutory regulation or exceeds the permitted use, you will need to obtain permission directly from the copyright holder. To view a copy of this licence, visit http://creativecommons.org/licenses/by/4.0/. The Creative Commons Public Domain Dedication waiver (http://creativecommons.org/publicdomain/zero/1.0/) applies to the data made available in this article, unless otherwise stated in a credit line to the data. 
(Continued from previous page)

Intervention and Comparator: COVID- 19 confirmed patients (using the RT-PCR test or CT scan) will be randomly assigned to one of two groups. The intervention group (Arms1) will be treated with lopinavir / ritonavir (Kaletra) + high dose Interferon- $\beta$ 1a (Recigen) and the control group will be treated with lopinavir / ritonavir (Kaletra) + low dose Interferon- $\beta$ 1a (Recigen) (the base therapeutic regimen). Both groups will receive standard care consisting of the necessary oxygen support, non-invasive, or invasive mechanical ventilation.

Main outcomes: Primary outcome: Time to clinical improvement is our primary outcome measure. This is an improvement of two points on a seven-category ordinal scale (recommended by the World Health Organization: Coronavirus disease (COVID-2019) R\&D. Geneva: World Health Organization) or discharge from the hospital, whichever comes first.

Secondary outcomes: mortality from the date of randomization until the last day of the study which will be the day all of the patients have had at least one of the following outcomes: 1) Improvement of two points on a seven-category ordinal scale. 2) Discharge from the hospital 3) Death. Improvement of SPO2 during the hospitalization, duration of hospitalization from date of randomization until the date of hospital discharge or death, whichever comes first. The incidence of new mechanical ventilation uses from the date of randomization until the last day of the study and the duration of it will be extracted. Please note that we are trying to add further secondary outcomes and this section of the protocol is still evolving.

Randomization: Eligible patients with confirmed SARS-Cov-2 infections will be randomly assigned in a 1:1 ratio to two therapeutic arms using permuted, block-randomization to balance the number of patients allocated to each group. The permuted block (three or six patients per block) randomization sequence will be generated, using Package 'randomizeR' in R software version 3.6.1. and placed in individual sealed and opaque envelopes by the statistician. The investigator will enroll the patients and only then open envelopes to assign patients to the different treatment groups. This method of allocation concealment will result in minimum selection and confounding biases.

Blinding (Masking): The present research is open-label (no masking) of patients and health care professionals who are undertaking outcome assessment of the primary outcome - time to clinical improvement.

Numbers to be randomised (sample size): Of the 100 patients randomised, 50 patients will be assigned to receive high dose Interferon beta-1a plus lopinavir/ritonavir (Kaletra), 50 patients will be assigned to receive low dose Interferon beta 1a plus lopinavir/ritonavir (Kaletra).

Trial Status: Protocol version 1.2.1. Recruitment is finished, the start date of recruitment was on August $20^{\text {th }} 2020$, and the end date was on September $4^{\text {th }}$ 2020. Last point of data collection will be the last day on which all of the 100 participants have had an outcome of clinical improvement or death, up to 14th days after hospitalization.

Trial registration: This study was registered with National Institutes of Health Clinical trials (www.clinicaltrials.gov; identification number NCT04521400, https://clinicaltrials.gov/ct2/show/NCT04521400, registered August 18, 2020 and first available online August 20, 2020).

Full protocol: The full protocol is attached as an additional file, accessible from the Trials website (Additional file 1). In the interest in expediting dissemination of this material, the familiar formatting has been eliminated; this Letter serves as a summary of the key elements of the full protocol.

Keywords: COVID-19, SARS-COV-2, Randomized controlled trial, lopinavir/ritonavir, Interferon- $\beta$ 1a

\section{Supplementary information}

Supplementary information accompanies this paper at https://doi.org/10. 1186/s13063-020-04812-2.

Additional file 1.

\section{Acknowledgements}

The authors would like to thank the Clinical Research Development Unit (CRDU) of Loghman Hakim Hospital, Shahid Beheshti University of Medical Sciences, Tehran, Iran for their support.

\section{Authors' contributions}

FH and MMR prepared the first draft. IAD and MAP edited the first draft. $M M R, F H$ and IAD finalized all drafts and approved the final version of the manuscript. IAD, FH and MMR conceived of the study and provided overall guidance. IAD supervised the process. All authors provided data or reviewed the manuscript, and approved the final version of the manuscript.

Funding

This research is unfunded.

\author{
Availability of data and materials \\ All the authors will have access to the final trial dataset. Furthermore, the \\ data set the data will be available from the author on reasonable request \\ (Contact: ilad13@yahoo.com)
}

Ethics approval and consent to participate

The present study was approved by the Ethics in Medical Research Committee of the Shahid Beheshti University of Medical Sciences with an 
Approval number of IR.SBMU.RETECH.REC.1399.033. I certify that we will also obtain informed consent from all participants to participate in the study. The informed consent form is available in Farsi from the corresponding author on request.

\section{Consent for publication}

Not applicable.

\section{Competing interests}

The authors declare that they have no competing interests.

\section{Author details}

'Infectious Diseases and Tropical Medicine Research Center, Shahid Beheshti University of Medical Sciences, Tehran, Iran. ${ }^{2}$ Department of Infectious Diseases, Loghman Hakim Hospital, Shahid Beheshti University of Medical Sciences, Tehran, Iran. ${ }^{3}$ Gastroenterology and Liver Diseases Research Center, Research Institute for Gastroenterology and Liver Diseases, Shahid Beheshti University of Medical Sciences, Tehran, Iran. ${ }^{4}$ Student Research Committee, Department of Clinical Pharmacy, School of Pharmacy, Shahid Beheshti University of Medical Sciences, Tehran, Iran. ${ }^{5}$ Anesthesiology Research Center Loghman Hakim Hospital, Shahid Beheshti University of Medical Sciences, Tehran, Iran.

Received: 13 October 2020 Accepted: 16 October 2020

Published online: 26 October 2020

\section{Publisher's Note}

Springer Nature remains neutral with regard to jurisdictional claims in published maps and institutional affiliations.

Ready to submit your research? Choose BMC and benefit from:
- fast, convenient online submission
- thorough peer review by experienced researchers in your field
- rapid publication on acceptance
- support for research data, including large and complex data types
- gold Open Access which fosters wider collaboration and increased citations
- maximum visibility for your research: over 100M website views per year
At BMC, research is always in progress.
Learn more biomedcentral.com/submissions

